\title{
Effect of explant plant source and acetosyringone concentration on transformation efficiency of wheat cultivars
}

\author{
Hamid Rashid ${ }^{1 \star}$, Zubeda Chaudhry ${ }^{2}$ and Mohammad Haroon Khan ${ }^{1}$ \\ ${ }^{1}$ Department of Bioinformatics, Mohammad Ali Jinnah University, Islamabad, Pakistan. \\ ${ }^{2}$ Department of Botany, Hazara University, Mansehra, NWFP, Pakistan.
}

Accepted 28 September, 2010

\begin{abstract}
Gene introduction into crop plants through genetic manipulation is a better alternative to conventional breeding for the improvement of stress tolerance. Agrobacterium-mediated transformation offers precise integration of genes into the genome with enhanced transgene stability. There are a number of factors which influence the rate of genetic transformation. The theme of this study is to exploit the explant source and acetosyringone concentration for the efficient development of Agrobacteriummediated gene delivery system in wheat cultivars Inqilab 91 and Chakwal 97. Seedlings, mature embryos and calli used as explant sources for transformation in both the cultivars showed positive response. It was further observed that mature embryos produced maximum transformation efficiencies of $\mathbf{4 0 . 0}$ and $36.25 \%$ with 37.5 and $31.03 \%$ of regeneration frequencies of transgenic plants for Chakwal 97 and Inqilab 91, respectively. Seedlings produced 33.75 and $27.5 \%$ while calli produced 26.25 and $\mathbf{2 2 . 5 \%}$ transformation efficiencies for both the cultivars. Acetosyringone concentration is also a limiting factor in transformation experiments especially in the case of cereals crop. Different concentrations of acetosyringone were used at the time of co-cultivation for optimization of the transformation protocol and maximum transformation efficiencies of 52.44 and $47.56 \%$ were obtained with $50 \mu \mathrm{M}$ of acetosyringone from the cultivars Chakwal 97 and Inqilab 91, respectively.
\end{abstract}

Key words: Wheat, agrobacterium, transformation, explant, acetosyringone.

\section{INTRODUCTION}

In Pakistan, the major staple food is wheat which is grown over an area of more than eight million hectares, hence is the largest grown crop. It shares 3\% in GDP (Gross Domestic Product) and $14.1 \%$ as a whole in agriculture (Ahmad, 2009). Plant breeders are providing considerable attention to wheat genetic improvement from the past few years to minimize losses due to pests

*Corresponding author. E-mail: drhamid@jinnah.edu.pk. Tel: 92-51-111 8787 87, Ext. 135, 92-301-5453378.

Abbreviations: As, Acetosyringone; Kn, kinetin; IAA, indole 3acetic acid; BAP, 6-benzylaminopurine; 2iP, 6-(gamma, gamma-dimethylallylamino) purine; 2,4-D, 2,4dichlorophenoxyacetic acid; GUS, beta-glucuronidase; X-Gluc, 5-bromo-4-chloro-3-indolyl- $\beta$-D-glucuronic acid. and pathogens and also to improve the grain yield (Pingali and Rajaram, 1999). Progress in crops genetic improvement for stress resistance is limited due to poor understanding of the mechanism and availability of efficient techniques for selecting breeding resources for stress resistance (Bhatti and Chaozu, 2009).

Genetic transformation is a promising alternative to conventional breeding for the introduction of genes into plants (Xing et al., 2008). Due to the speedy development in the field of genetic engineering, it has offered a promising approach to improve stress tolerance (Ramanjulu and Bartels, 2002; Islam et al., 2007). Agrobacteriummediated transformation facilitates the precise integration of genes into the plant genome (Shou et al., 2004; Karami et al., 2009), however, this system is affected by a number of factors including tissue culture conditions, acetosyringone concentration, explant source etc (Briza et al., 2008; Cho et al., 2008). The theme of this study is 
to exploit the explant source and acetosyringone concentration for the efficient development of Agrobacteriummediated gene delivery system in local cultivars of wheat.

\section{MATERIALS AND METHODS}

Seedlings, embryos and calli of two wheat cv. Chakwal-97 and Inqilab-91 were used as explant sources in this study. MS (Murashige and Skoog, 1962) media supplemented with $3 \mathrm{mg} / \mathrm{l}$ 2,4D was used for initiating callus from the explants. The cultures were incubated in growth room at $25 \pm 1^{\circ} \mathrm{C}$ for 20 days for proliferation. After 20 days, the calli were shifted to maintenance medium that is, MS medium containing $3 \mathrm{mg} / \mathrm{l}$ 2,4-D. 20 days old calli were used for transformation with Agrobacterium strain EHA101 containing binary vector plG121Hm. Explants were co-cultivated with the Agrobacterium for $1 \mathrm{~min}$ and then blotted dry. Co-cultivation plates contained callus induction medium $(\mathrm{CIM})+$ different concentrations of As (Acetosyringone) that is, $0.0,50$ and $100 \mu \mathrm{M}$. These plates were placed at $28^{\circ} \mathrm{C}$ in dark for $1-2$ days. Then the explants were disinfected with $500 \mathrm{mg} / \mathrm{l}$ cefotaxime and were transferred to selection medium (MS media + $3 \mathrm{mg} / \mathrm{l} 2,4-\mathrm{D}+50 \mathrm{mg} / \mathrm{l}$ hygromycin and $500 \mathrm{mg} / \mathrm{l}$ cefotaxime) for 30 days. The transformed explants were shifted to regeneration media containing different growth regulators (2ip, IAA, BAP and $\mathrm{Kn}$ ) and $50 \mathrm{mg} / \mathrm{l}$ hygromycin and 500 $\mathrm{mg} / \mathrm{l}$ cefotaxime. Some of the explants were selected at random for GUS assay after 15 days of selection and were incubated in X-Gluc solution at $37^{\circ} \mathrm{C}$ for $2-3$ days for confirmation of transformation.

\section{RESULTS AND DISCUSSION}

\section{Callus induction}

Calli were induced from seedlings and mature embryos of two wheat cultivars (Inqilab 91 and Chakwal 97) on MS medium with four different concentrations of 2,4-D that is, 2.0, 3.0, 4.0 and $5.0 \mathrm{mg} / \mathrm{l}$. In addition, a control combination on MS medium without 2,4-D was also kept to compare the results. Highest percentage of 76.0 and 61.0 were achieved from Inqilab 91 and Chakwal 97 respectively with $3 \mathrm{mg} / \mathrm{l}$ of 2,4-D. No callus induction was recorded without 2,4-D (Table-1). Nasircilar et al. (2006) obtained best results of callus induction with $2.0 \mathrm{mg} / \mathrm{l}$ of 2,4-D in MS medium for different wheat cultivars. Haliloglu (2002) observed highest embryogenic callus formation from immature embryos of wheat on MS+B5 medium with $2.0 \mathrm{mg} / \mathrm{l}$ of 2,4-D. These results with slight difference in concentration of 2,4-D may be due to difference in genotypes because varied concentration of 2,4-D have been recorded for different genotypes by Arzani and Mirodjagh (1999). Shah et al. (2003) recorded best callus induction at $3.5 \mathrm{mg} / \mathrm{l}$ and good callus induction at $3.0 \mathrm{mg} / \mathrm{l}$ of 2,4-D. Malik et al. (2004) found $3.5 \mathrm{mg} / \mathrm{l}$ of 2,4-D concentration in LS medium as the most appropriate callus induction and proliferation from mature seeds in wheat cultivars. These results are in line with our study and $3.0 \mathrm{mg} / \mathrm{l}$ of 2,4-D was best for callus induction. Rahman et al. (2008) achieved best callus induction with $6.0 \mathrm{mg} / \mathrm{l}$ of 2,4-D from seeds and mature embryos which is quite in contrast with the present study.

\section{Regeneration of calli}

Regeneration of calli derived from seedlings and mature embryos of wheat was carried out with two different combinations of growth regulators in MS medium. Maximum regeneration of 75 and $71 \%$ was observed from the mature embryos derived calli of Inqilab 91 and Chakwal 97 respectively with BAP $(1 \mathrm{mg} / \mathrm{L})+$ Kinetin $(0.5 \mathrm{mg} / \mathrm{L})$ +2iP $(0.5 \mathrm{mg} / \mathrm{L})$. Rashid et al. (2002) achieved best regeneration with $0.1 \mathrm{mg} / \mathrm{l}$ of IAA and $0.5 \mathrm{mg} / \mathrm{l}$ of BAP in wheat. cv Rawal-87. Alizadeh et al. (2004) found $1 \mathrm{mg} / \mathrm{l}$ of BAP, $0.2 \mathrm{mg} / \mathrm{l} \mathrm{IAA}$ and $0.2 \mathrm{mg} / \mathrm{l}$ of $2,4-\mathrm{D}$ as a best combination for shoot regeneration from embryos and 0.2 $\mathrm{mg} / \mathrm{l} 2,4-\mathrm{D}$ and $2 \mathrm{mg} / \mathrm{l}$ BAP as a best combination for shoot regeneration in excised embryo explants. Shah et al. (2003) found $2 \mathrm{mg} / \mathrm{l} \mathrm{BAP}$ and $1.0 \mathrm{mg} / \mathrm{l} \mathrm{IAA}$ as best combination for plantlet regeneration and also found $\mathrm{Kn}$ good regeneration (Table 2).

\section{Effect of explant source on transformation efficiency}

Three different explant sources (seedlings, mature embryos and calli) were used for transformation in two wheat cultivars Chakwal 97 and Inqilab 91. All the explant sources used for transformation in both the cultivars showed positive response. It was observed that mature embryos produced maximum transformation efficiencies of 40.0 and $36.25 \%$ and maximum regeneration frequencies of 37.5 and 31.03 for Chakwal 97 and Inqilab 91 respectively. Seedlings produced 33.75 and $27.5 \%$ while calli produced 26.25 and $22.5 \%$ transformation efficiencies for both cultivars (Table 3). Type of explant was found to affect transformation efficiency (Lengliz et al., 2009). Sarker and Biswas (2002) tested four different explants for their transformation ability and obtained maximum transformation from immature embryos derived calli. Patnaik and Khurana (2003) used mature embryo derived calli of Triticum aestivum and $\mathrm{T}$. durum for transformation through particle bombardment and obtained the transformation frequency of 7.7 and $10 \%$, respectively. Mature embryos of $\mathrm{T}$. aestivum cv. CPAN1676 and T. durum cv. PDW215 were co-cultivated with Agrobacterium tumefaciens LBA4404 (pBl101::Act1) and achieved transformation efficiency of $5.57 \%$ (Patnaik et al., 2006).

\section{Effect of acetosyringone concentration on transformation efficiency}

Different concentrations of acetosyringone $(0,50$ and 100 $\mu \mathrm{M})$ were used at the time of co-cultivation and in the cocultivation plates. Maximum transformation efficiencies of 52.44 and $47.56 \%$ were obtained with $50 \mu \mathrm{M}$ of acetosyringone from the cultivars Chakwal 97 and Inqilab 91 respectively (Table 4). These results are supported by the results of McCormac et al. (1998) who used $100 \mu \mathrm{M}$ 
Table 1. Percentage of calli derived from seedlings and mature embryos with different concentrations of 2,4-D.

\begin{tabular}{lcccc}
\hline \multirow{2}{*}{ Concentrations of 2,4-D (mg/l) $)$} & \multicolumn{2}{c}{ Inqilab 91 } & \multicolumn{1}{c}{ Chakwal 97 } \\
\cline { 2 - 5 } & Seedlings & Mature embryos & Seedlings & Mature embryos \\
\hline 0.0 & 0.0 & 0.0 & 0.0 & 0.0 \\
2.0 & 34 & 42 & 41 & 58 \\
3.0 & 62 & 76 & 56 & 61 \\
4.0 & 32 & 38 & 35 & 40 \\
5.0 & 21 & 26 & 25 & 31 \\
\hline
\end{tabular}

Values are percentage in round figures.

Table 2. Regeneration percentage of calli derived from seedling and mature embryos on regeneration medium with different combinations of growth regulators.

\begin{tabular}{lcccc}
\hline \multirow{2}{*}{ Variety } & \multicolumn{1}{c}{ IAA $(\mathbf{0 . 1} \mathbf{~ m g} / \mathbf{L})+$ BAP $(\mathbf{1 ~} \mathbf{~ g} / \mathbf{L})$} & BAP $(\mathbf{1 ~} \mathbf{~ g} / \mathbf{L})+$ Kinetin $(\mathbf{0 . 5} \mathbf{~ m g} / \mathbf{L})+\mathbf{2 i P}(\mathbf{0 . 5} \mathbf{~ m g} / \mathbf{L})$ \\
\cline { 2 - 5 } & $\mathbf{C 1}$ & $\mathbf{C 2}$ & $\mathbf{C 1}$ & C2 \\
\hline Inqilab 91 & 46 & 52 & 60 & 75 \\
Chakwal 97 & 49 & 55 & 57 & 71 \\
\hline
\end{tabular}

C1 = Seedlings derived calli; $\mathrm{C} 2$ = mature embryos derived calli.

Table 3. Transformation efficiency of wheat cultivars using different explants at $50 \mu \mathrm{M}$ acetosyringone.

\begin{tabular}{lccccccccc}
\hline \multicolumn{1}{c}{ ES } & TNE & CSGA & GPC & PGA & TCSH & SEH & TE & PF & RFT \\
\hline Chakwai 97 & & & & & & & & & \\
\hline E1 & 100 & 20 & 9 & 45 & 80 & 27 & 33.75 & 7 & 25.93 \\
E2 & 100 & 20 & 13 & 65 & 80 & 32 & 40.0 & 12 & 37.5 \\
E3 & 100 & 20 & 7 & 35 & 80 & 21 & 26.25 & 5 & 23.80 \\
\hline Inqilab 91 & & & & & & & & & \\
\hline E1 & 100 & 20 & 7 & 35 & 80 & 22 & 27.5 & 4 & 18.18 \\
E2 & 100 & 20 & 11 & 55 & 80 & 29 & 36.25 & 9 & 31.03 \\
E3 & 100 & 20 & 6 & 30 & 80 & 18 & 22.5 & 4 & 2222 \\
\hline
\end{tabular}

$\mathrm{ES}=$ Explant source, $\mathrm{E} 1=$ seedlings,$\quad \mathrm{E} 2=$ mature embryos, $\mathrm{E} 3=$ calli, TNE $=$ total number of explants, CSGA = calli selected for GUS activity, PGA = percentage of GUS analysis, SEH = selected explants on hygromycin, GPC = GUS positive calli, $\mathrm{PF}=$ plantlet formation, $\mathrm{TCSH}=$ total calli for selection on hygromycin, TE = transformation efficiency (\%), and RFT = regeneration frequency of transgenic plants.

Table 4. Transformation efficiency of wheat cultivars using mature embryos as explant source with different concentrations of acetosyringone.

\begin{tabular}{lccccccc}
\hline \multicolumn{1}{c}{ AC } & TNE & CSGA & GPC & PGA & TCSH & SEH & TE \\
\hline Chakwal 97 & & & & & & & \\
\hline 0.0 & 100 & 18 & 0 & 0.0 & 82 & 0 & 0.0 \\
50.0 & 100 & 18 & 11 & 61.11 & 82 & 43 & 52.44 \\
100.0 & 100 & 18 & 7 & 38.9 & 82 & 31 & 37.80 \\
\hline Inqilab 91 & & & & & & & \\
\hline 0.0 & 100 & 18 & 0 & 0.0 & 82 & 0 & 0.0 \\
50.0 & 100 & 18 & 9 & 50.0 & 82 & 39 & 47.56 \\
100.0 & 100 & 18 & 6 & 33.33 & 82 & 27 & 32.93 \\
\hline
\end{tabular}

$\mathrm{AC}=$ Acetosyringone concentration in $\mathrm{Mm}, \mathrm{TNE}=$ total number of explants, CSGA = calli selected for GUS activity, $\mathrm{PGA}=$ percentage of GUS analysis, SEH = selected explants on hygromycin, GPC $=$ GUS positive calli, TCSH $=$ total calli for selection on hygromycin, and TE = transformation efficiency (\%). 
As and found that presence of As increase the efficiency of transformation. When they used $100 \mu \mathrm{M}$ of As, transformation efficiency was $46.15 \%$ while in the absence of As, the efficiency was $6.66 \%$. Ke et al. (2002) added 100 $\mu \mathrm{M}$ As to inoculation and co-cultivation media and observed development of GUS loci within the shoot and root structures. Amoah et al. (2001) added As to final concentration of $200 \mu \mathrm{M}$ and obtained increased number of explants producing blue spots. The present study can further be improved by testing the impact of higher concentrations of As such as 150 and $200 \mu \mathrm{M}$ on efficiency of transformation. The mature embryos after 15 days of selection were tested for transient GUS expression. In case of $0 \mu \mathrm{M}$ of As, no GUS expression was observed. Maximum GUS expression was observed by using $50 \mu \mathrm{M}$ of As.

In the present study an efficient transformation protocol was developed by exploiting explant source and acetosyringone concentration which will lead to the further improvement of wheat quality as well as yield globally.

\section{REFERENCES}

Ahmad F (2009). Food security in Pakistan. Pak. J. Agric. Sci. 46(2): 83-89.

Alizadeh H, Naghave MR, Omidi M, Saatian B (2004). Effect of plant growth regulators on direct shoot regeneration of wheat (Triticum aestivum L.). New direction for a diverse planet: Proceeding of the $4^{\text {th }}$ International Crop Congress Brisbane, Australia, 26 Sep-1 Oct.

Amoah BK, Wu H, Sparks C, Jones HD (2001). Factors influencing Agrobacterium-mediated transient expression of uidA in wheat inflorescence tissue. J. Exp. Bot. 52: 1135-1142.

Arzani A, Mirodjagh SS (1999). Response of durum wheat cultivars to immature embryo culture, callus induction and in vitro salt stress. Plant Cell Tissue Organ Cult. 58: 67-72.

Bhatti KH, Chaozu H (2009). Agrobacterium mediated tobacco transformation with rice $F A E$ gene and segregation analysis of $\mathrm{T} 1$ generation. Pak. J. Bot. 41(1): 403-412.

Briza J, Pavingerova D, Prikrylova P, Gazdova J, Vlasak J, Niedermeierova $H$ (2008). Use of phosphomannose isomerasebased selection system for Agrobacterium-mediated transformation of tomato and potato. Biol. Plant. 52: 453-461.

Cho MA, Moon CY, Liu JR, Choi PS (2008). Agrobacterium-mediated transformation in Citrullus lanatus. Biol. Plant, 52: 365-369.

Haliloglu K (2002). Wheat immature embryo culture for embryogenic callus induction. J. Biol. Sci. 2(8): 520-521.

Islam A, Hassairi A, Reddy VS (2007). Analysis of molecular and morphological characteristics of plants transformed with antifungal gene. B. J. Bot. 361: 47-52.

Karami O, Esna AM, Kurdistani GK, Aghavaisi B (2009). Agrobacterium-mediated genetic transformation of plants: the role of host. Biol. Plant. 53(2): 201-212.

Ke XY, McCormac AC, Harvey A, David L, Dong FC, Malcolm CE (2002). Manipulation of discriminatory T-DNA delivery by Agrobacterium into cells of immature embryos of barley and wheat. Euphytica, 126: 333-343.

Lengliz R, Gorsane F, Majoul H, Fakhfakh H (2009). Molecular and phenotypical characterization of transgenic tomato plants: Solanum lycopersicon. Acta Hortic. (ISHS) 823: 33-40.
Malik SI, Rashid H, Yasmin T, Minhas NM (2004). Effect of 2,4dichlorophenoxyacetic acid on Callus Induction from Mature Wheat (Triticum aestivum L.) Seeds. Int. J. Agric. Biol. 6(1): 156-159.

McCormac AC, Wu H, Bao M, Wang Y, Xu R, Elliot MC, Chen DF (1998). The use of visual marker genes as cell-specific reporters of Agrobacterium-mediated T-DNA delivery to wheat (Triticum aestivum L.) and barley (Hordeum vulgare L.). Euphytica, 99: 17-25.

Murashige T, Skoog F (1962). A revised medium for rapid growth and bioassays with tobacco tissue cultures. Physiol. Plant, 15: 473-497.

Nasircilar AG, Turgut K, Fiskin K (2006). Callus induction and plant regeneration from mature embryos of different wheat genotypes. Pak. J. Bot. 38(2): 637-645.

Patnaik D, Khurana P (2003). Genetic transformation of Indian bread ( $T$. aestivum) and pasta (T.durum) wheat by particle bombardment of mature embryo-derived calli. BMC Plant Biol. 3: p. 5.

Patnaik D, Vishnudasan D, Khurana P (2006). Agrobacterium mediated transformation of mature embryos of Triticum aestivum and Triticum durum. Curr. Sci. 91(3): 307-317.

Pingali PL, Rajaram S (1999). Global wheat research in a changing world: Options for sustaining growth in wheat productivity. In: Cimmyt. World Wheat Facts and Trends. D.F., Mexico: pp. 1-18.

Rahman MM, Shamsuddin AKM, Asad U (2008). In Vitro Regeneration from Mature Embryos in Spring Wheat. Int. J. Sustain. Crop Prod. 3(2): 76-80.

Ramanjulu S, Bartels D (2002). Drought- and desiccation-induced modulation of gene expression in plants. Plant Cell Environ. 25: 141151.

Rashid H, Ghani RA, Chaudhry Z, Naqvi SMS, Quraishi A (2002). Effect of media, growth regulators and genotypes on callus induction and regeneration in wheat (Triticum aestivum L.). J. Biotechnol. 1(1): 4954.

Sarker RH, Biswas A (2002). In vitro Plantlet Regeneration and Agrobacterium mediated Genetic Transformation of Wheat (Triticum aestivum L.). Plant Tissue Cult. 12(2): 155-165.

Shah MI, Jabeen M, Ilahi I (2003). In vitro callus induction, its proliferation and regeneration in seed explants of wheat (Triticum aestivum L.) var. LU-26S. Plant J. Bot. 35(2): 209-217.

Shou H, Frame BR, Whitham SA, Wang K (2004). Assessment of transgenic maize events produced by particle bombardment or Agrobacterium-mediated transformation. Mol. Breed. 13: 201-208.

Xing YJ, Ji Q, Yang Q, Luo YM, Li Q, Wang X (2008). Studies on Agrobacterium-mediated genetic transformation of embryogenic suspension cultures of sweet potato. Afr. J. Biotechnol. 7(5): 534540 . 